\title{
COVID-19 and Venous Thromboembolism Pharmacologic Thromboprophylaxis
}

\author{
Cassandra Benge, PharmD; and Bishoy Ragheb, PharmD
}

Background: Coagulopathy has emerged as a hallmark issue of the coronavirus 2019 (COVID-19). Medical facilities are faced with the challenge of developing institutional thromboprophylaxis protocols; however, due to the novelty of the disease, there is a dearth of high-quality, prospective evidence for decision making.

Observations: The US National Institutes of Health along with 4 leading societies in the fields of thrombosis and hemostasis have published guidance based on expert consensus that helps provide a framework for local policy development. While there is agreement in a few areas, there are notable and sometimes considerable differences in recommendations that facilities should discuss when developing local guidance.

Conclusions: This document aims to streamline and simplify the available guidance so health care providers can readily identify consensus and divergence of COVID-19 thromboprophylaxis recommendations. Additionally, the authors provide and briefly highlight the COVID-19 thromboprophylaxis protocol of the US Department of Veterans Affairs Tennessee Valley Healthcare System in Nashville and Murfreesboro to serve as an example of a guideline-directed approach for order-set development.

\section{Cassandra Benge is a Clinical Pharmacy Specialist, Surgical Intensive Care Unit, and Bishoy Ragheb is a Clinical Pharmacy Specialist, Anticoagulation, both at Veterans Affairs Tennessee Valley Healthcare System in Nashville/Murfreesboro. \\ Correspondence: Cassandra Benge (cassiebenge@gmail.com)}

Fed Pract. 2020;37(11):506-511. doi:10.12788/fp.0063
T he novel coronavirus SARS-CoV-2 and resulting viral syndrome (COVID-19) was first reported in China during December 2019 and within weeks emerged in the US. ${ }^{1}$ Since it is a rapidly evolving situation, clinicians must remain current on best practices-a challenging institutional responsibility. According to LitCovid, a curated literature hub for tracking scientific information on COVID-19, there are $>54,000$ articles on the subject in PubMed.

Among these include venous thromboembolism (VTE) prophylaxis guidance from 4 respected thrombosis organizations/societies and the US National Institutes of Health. ${ }^{1-5}$

\section{OBSERVATIONS}

COVID-19 predisposes patients with and without a history of cardiovascular disease to thrombotic complications, occurring in either the venous or arterial circulation system. ${ }^{2,6}$ Early observational studies suggest that thrombotic rates may be in excess of 20 to 30\%; however, the use of prophylactic anticoagulation was inconsistent among studies that were rushed to publication. ${ }^{6}$

Autopsy data have demonstrated the presence of fibrin thrombi within distended small vessels and capillaries and extensive extracellular fibrin deposition. ${ }^{6}$ Investigators compared the characteristics of acute pulmonary embolism in 23 cases with COVID-19 but with no clinical signs of deep vein thrombosis with 100 controls without COVID-19. ${ }^{7}$ They observed that throm- botic lesions had a greater distribution in peripheral lung segments (ie, peripheral arteries) and were less extensive for those with COVID-19 vs without COVID-19 infection. Thus, experts currently hypothesize that COVID-19 has a distinct "pathomechanism." As a unique phenotype, thrombotic events represent a combination of thromboembolic disease influenced by components of the Virchow triad (eg, acute illness and immobility) and in situ immunothrombosis, a local inflammatory response. ${ }^{6,7}$

Well-established surgical and nonsurgical VTE thromboprophylaxis guidelines serve as the foundation for current COVID19 thromboprophylaxis guidance..$^{8,9}$ Condition specific guidance is extrapolated from small, retrospective observational studies or based on expert opinion, representing levels 2 and 3 evidence, respectively. ${ }^{1-5}$ Table 1 captures similarities and differences among COVID-19 VTE thromboprophylaxis recommendations which vary by time to publication and by society member expertise gained from practice in the field.

Three thrombosis societies recommend universal pharmacologic thromboprophylaxis for acutely ill COVID-19 patients who lack contraindications. ${ }^{3-5}$ Others recommend use of risk stratification scoring tools, such as the Padua risk assessment model (RAM) for medical patients or Caprini RAM for surgical patients, the disseminated intravascular coagulation (DIC) score, or the sepsis-induced coagulopathy score to determine therapeutic appropriateness (Tables 2 and 3). ${ }^{1,2}$ Since 
most patients hospitalized for COVID-19 will present with a pathognomonic pneumonia and an oxygen requirement, they will generally achieve a score of $\geq 4$ when the Padua RAM is applied; thus, representing a clear indication for pharmacologic thromboprophylaxis. ${ }^{8,9}$ If the patient is pregnant, the Anticoagulation Forum recommends pharmacologic prophylaxis, consultation with an obstetrician, and use of obstetrical thromboprophylaxis guidelines. ${ }^{3,10,11}$

Most thrombosis experts prefer parenteral thromboprophylaxis, specifically low molecular-weight heparin (LMWH) or fondaparinux, for inpatients over use of direct oral anticoagulants (DOACs) in order to minimize the potential for drug interactions particularly when investigational antivirals are in use. ${ }^{4}$ Once-daily agents (eg, rivaroxaban, fondaparinux, and enoxaparin) are preferred over multiple daily doses to minimize staff contact with patients infected with COVID-19. ${ }^{4,5}$ Fondaparinux and DOACs should preferentially be used in patients with a recent history of heparin-induced thrombocytopenia with and without thrombosis (HIT/HITTS). Subcutaneous heparin is reserved for patients who are scheduled for invasive procedures or have reduced renal function (eg, creatinine clearance $<30 \mathrm{~mL} / \mathrm{min}$ ). , $^{1,-5}$ In line with existing pharmacologic thromboprophylaxis guidance, standard prophylactic LMWH doses are recommended unless patients are obese (body mass index [BMI] $>30$ ) or morbidly obese (BMI > 40) necessitating selection of intermediate doses. ${ }^{4}$

Since early non-US studies demonstrated high thrombotic risk without signaling a potential for harm from pharmacologic thromboprophylaxis, some organizations recommend empiric escalation of anticoagulation doses for critical illness. ${ }^{3,4,6}$ Thus, it may be reasonable to advance to either intermediate pharmacologic thromboprophylaxis dosing or therapeutic doses. ${ }^{3}$ However, observational studies question this aggressive practice unless a clear indication exists for intensification (ie, atrial fibrillation, known VTE).

A large multi-institutional registry study that included 400 subjects from 5 centers demonstrated a radiographically confirmed VTE rate of $4.8 \%$ and an arterial thrombo- sis rate of $2.8 \% .{ }^{6}$ When limiting to the critically ill setting, VTE and arterial thrombosis occurred at slightly higher rates $(7.6 \%$ and $5.6 \%$, respectively). Patients also were at risk for nonvessel thrombotic complications (eg, CVVH circuit, central venous catheters, and arterial lines). Subsequently, the overall thrombotic complication rate was 9.5\%. All thrombotic events except one arose in patients who were receiving standard doses of pharmacologic thromboprophylaxis. Unfortunately, D-dimer elevation at admission was not only predictive of thrombosis and death, but portended bleeding. The overall bleeding rate was $4.8 \%$, with a major bleeding rate of $2.3 \%$. In the context of observing thromboses at normally expected rates during critical illness in association with a significant bleeding risk, the authors recommended further investigation into the net clinical benefit.

Similarly, a National Institutes of Health funded, observational, single center US study evaluated 4,389 inpatients infected with COVID-19 and determined that therapeutic and prophylactic anticoagulation reduced inpatient mortality (adjusted hazard ratio [aHR], 0.53 and 0.50 , respectively for the primary outcome) and intubation (aHR, 0.69 and 0.72 , respectively) over no anticoagulation. ${ }^{12}$ Notably, use of inpatient therapeutic anticoagulation commonly represented a continuation of preadmission therapy or progressive COVID-19. A subanalysis demonstrated that timely use (eg, within 48 hours of admission) of prophylactic or therapeutic anticoagulation, resulted in no difference $(P<.08)$ in the primary outcome. Bleeding rates were low overall: $3 \%, 1.7 \%$, and $1.9 \%$ for therapeutic, prophylactic, and no anticoagulation groups, respectively. Furthermore, selection of DOACs seems to be associated with lower bleeding rates when compared with that of LMWH heparin (1.3\% vs $2.6 \%$, respectively). In those where site of bleeding could be ascertained, the most common sites were the gastrointestinal tract $(50.7 \%)$ followed by mucocutaneous (19.4\%), bronchopulmonary (14.9\%), and intracranial (6\%). In summary, prophylactic thromboprophylaxis doses seem to be associated with positive net clinical benefit.

As of October 30, 2020, the US Department of Veterans Affairs (VA) had reported 75,156 COVID-19 cases and 3,961 deaths. ${ }^{13}$ 
TABLE 1 Society Recommendations for COVID-19 Thromboprophylaxis

\begin{tabular}{|c|c|c|c|c|}
\hline $\begin{array}{l}\text { Societies } \\
\text { (Guidance } \mathrm{mo} / \mathrm{y} \text { ) }\end{array}$ & $\begin{array}{l}\text { Universal } \\
\text { thromboprophylaxis } \\
\text { in acutely ill } \\
\text { inpatients }\end{array}$ & $\begin{array}{l}\text { Pharmacologic prophylaxis options in } \\
\text { acutely ill inpatients }\end{array}$ & $\begin{array}{l}\text { Role for } \\
\text { intensification of } \\
\text { pharmacologic } \\
\text { prophylaxis in } \\
\text { acutely ill inpatients }\end{array}$ & $\begin{array}{l}\text { Universal thromboprophylaxis in } \\
\text { labor and delivery }\end{array}$ \\
\hline NIH $(5 / 2020)^{1}$ & $\begin{array}{l}\text { No; follow the } \\
\text { standard of care; } \\
\text { data suggest use } \\
\text { when the sepsis- } \\
\text { induced } \\
\text { coagulopathy } \\
\text { score } \geq 4\end{array}$ & Follow the standard of care & No & $\begin{array}{l}\text { No; manage pregnant patients } \\
\text { with COVID-19 for the same } \\
\text { conditions that require } \\
\text { anticoagulation in pregnancy; } \\
\text { follow guidance recently } \\
\text { published by ASH/ACOG }\end{array}$ \\
\hline ACC $(4 / 2020)^{2}$ & $\begin{array}{l}\text { No; for patients with } \\
\text { moderate or severe } \\
\text { COVID-19 without } \\
\text { DIC, use risk } \\
\text { stratification tools } \\
\text { (Caprini, IMPROVE } \\
\text { model, or Padua } \\
\text { model) to assess risk }\end{array}$ & $\begin{array}{l}\text { For hospitalized patients with COVID-19 } \\
\text { without DIC, use prophylactic doses/ } \\
\text { regimens: DOAC (prophylactic doses), } \\
\text { enoxaparin ( } 40 \mathrm{mg} \text { SC daily), dalteparin } \\
\text { (5,000 U SC daily), or heparin (5,000 U } \\
\text { SC } 2-3 \text { times daily if renal dysfunction } \\
\text { present }[\mathrm{CrCl}<30 \mathrm{~mL} / \mathrm{min}] \text { ) }\end{array}$ & No & Not discussed \\
\hline $\begin{array}{l}\text { Anticoagulation } \\
\text { Forum }(5 / 2020)^{3}\end{array}$ & $\begin{array}{l}\text { Yes; use for all } \\
\text { nonpregnant } \\
\text { hospitalized patients } \\
\text { with confirmed or } \\
\text { highly suspected } \\
\text { COVID-19 }\end{array}$ & Standard dose VTE prophylaxis & Not discussed & $\begin{array}{l}\text { Yes; follow guidance recently } \\
\text { published by the RCOG; close } \\
\text { collaboration with obstetric and } \\
\text { anesthesiology colleagues is } \\
\text { recommended in the event of } \\
\text { delivery and/or need for epidural } \\
\text { anesthesia during hospitalization }\end{array}$ \\
\hline ISTH $(5 / 2020)^{4}$ & Yes & $\begin{array}{l}\text { Standard dose UFH or LMWH should be } \\
\text { used after careful assessment of bleed risk; } \\
\text { LMWH is preferred agent; regimens: } \\
\text { enoxaparin ( } 40 \mathrm{mg} \text { SC daily), or heparin } \\
(5,000-7,500 \mathrm{SC} \text { every } 8-12 \text { h); modify } \\
\text { recommendations based on extremes of } \\
\text { body weight, severe thrombocytopenia (ie, } \\
\text { platelet counts of } 10,000 \times 10^{9} / \mathrm{L} \text { or } 25,000 \\
\text { x } 10 \% / \mathrm{L}) \text { or deteriorating renal function }\end{array}$ & $\begin{array}{l}\text { Yes; intermediate } \\
\text { dose LMWH may } \\
\text { be reasonable } \\
\text { in non-ICU } \\
\text { hospitalized } \\
\text { COVID-19 } \\
\text { patients }\end{array}$ & Not discussed \\
\hline CHEST $(6 / 2020)^{5}$ & Yes & $\begin{array}{l}\text { LMWH or fondaparinux over UFH; and } \\
\text { additionally recommends LMWH, } \\
\text { fondaparinux, or UFH, over a DOAC }\end{array}$ & No & Not discussed \\
\hline
\end{tabular}

Abbreviations: ACC, American College of Cardiology; ACOG, American College of Obstetricians and Gynecologists; ASH, American Society of Hematology; CHEST, American College of Chest Physicians; CrCl, creatinine clearance; DIC, disseminated intravascular coagulation; DOAC, direct oral anticoagulants; ICU, intensive care unit; ISTH, International Society on Thrombosis and Haemostasis; LMWH, low molecular-weight heparin; NIH, National Institutes of Health; RCOG, Royal College of Obstetricians; SC, subcutaneous; UFH, unfractionated heparin.

aTreatment-dose heparin should not be considered for primary prevention.

Since the VA Pharmacy Benefits Management (PBM) does not disseminate nationally prepared anticoagulation order sets to the field, facility anticoagulation leads should be encouraged to develop local guidance-based policies to help standardize care and minimize further variations in practice, which would likely lack evidential support. Per the VA Tennessee Valley Healthcare System (TVHS)- Nashville/Murfreesboro anticoagulation policy, we limit the ordering of parenteral anticoagulation to Computerized Patient Record System (CPRS) order sets in order to provide decision support (eFigure 1, available at doi:10.12788/fp.0063). Other fa- cilities have shown that embedded clinical decision support tools increase adherence to guideline VTE prophylaxis recommendations within the VA. ${ }^{14}$

In April 2020, the TVHS anticoagulation clinical pharmacy leads developed a COVID19 specific order set based on review of societal guidance and the evolving, supportive literature summarized in this review with consideration of provider familiarity (eFigure 2 , available at doi:10.12788/fp.0063)). Between April and June 2020, the COVID-19 order set content consistently evolved with publication of each COVID-19 thromboprophylaxis guideline. ${ }^{1-5}$ 
Intervention when pharmacologic thromboprophylaxis is contraindicated
Universal thromboprophylaxis in critical illness
Pharmacologic prophylaxis options in critical illness

Role for

pharmacologic and mechanical thromboprophylaxis

Not discussed

There are insufficient data to recommend for or against the use of increasing anticoagulant doses; LMWH or UFH may be preferred due to shorter half-lives, ability to be administered IV or SC, and fewer drug-drug interactions compared with oral anticoagulants

Universal thromboprophylaxis in critical illness
Use standard doses/regimens: enoxaparin (SC $40 \mathrm{mg}$ daily), dalteparin (5,000 U SC daily), heparin (5,000 U 2-3 times SC daily if renal dysfunction present $[\mathrm{CrCl}<30 \mathrm{~mL} / \mathrm{min}])$
Intermittent pneumatic compression
Yes; for patients with moderate or severe COVID-19 without DIC, use risk stratification tools (Caprini, IMPROVE model, or Padua model) to assess risk; Yes; for patients with moderate or severe COVID-19 and DIC (note: the diagnosis of DIC is best established using the ISTH DIC score calculator)

Intermittent pneumatic compression devices with regular reassessment for conversion to pharmacologic prophylaxis

Yes

\section{Suggest increased doses:} enoxaparin (40 mg SC twice daily), enoxaparin $(0.5 \mathrm{mg} / \mathrm{kg} \mathrm{SC}$ twice daily), heparin $(7,500 \cup \mathrm{SC} 3$ times daily), or low-intensity heparin infusion
Yes; combination in critically ill patients is reasonable

\section{Not discussed}

Yes

\author{
Use standard prophylactic doses of \\ UFH or LMWH; an intermediate dose \\ can be considered in high-risk ICU \\ patients: \\ enoxaparin (40 mg 1-2 times daily), \\ enoxaparin (0.5 mg/kg 1-2 times daily), \\ prophylactic or treatment dose DOAC, or \\ heparin $\left(5,000-7,500 \mathrm{U}\right.$ every 8-12 h) ${ }^{\mathrm{a}}$
}

Yes; combination in severe COVID-19 is reasonable
Mechanical thromboprophylaxis in critically ill, COVID-19
Use standard dose anticoagulant thromboprophylaxis over intermediate or full treatment dosing, per existing guidelines; suggest LMWH over UFH and LMWH or UFH over fondaparinux or a DOAC
Yes

thromboprophylaxis over intermediate or
full treatment dosing, per existing guidelin
suggest LMWH over UFH and LMWH or
UFH over fondaparinux or a DOAC

Yes

No
Since TVHS is a high-complexity facility, we elected to use universal pharmacologic thromboprophylaxis for patients with COVID-19. This construct bypasses the use of scoring tools (eg, RAM), although we use Padua and Caprini RAMS for medical and surgical patients, respectively, who are not diagnosed with COVID-19. The order set displays all acceptable guideline recommended options, delineated by location of care (eg, medical ward vs intensive care unit), prior history of heparin-induced thrombocytopenia, and renal function. Subsequently, all potential agents, doses, and dosing interval options are offered so that the provider autonomously determines how to individualize the clinical care. Since TVHS has only diagnosed 932 ambulatory/ inpatient COVID-19 cases combined, our plans are to complete a future observational analysis to determine the effectiveness of the inpatient COVID-19 thromboprophylaxis order set for our internal customers.

\section{CONCLUSIONS}

The COVID-19 pandemic has resulted in arguably the most challenging medical climate in the evidence-based medicine era. Until high-quality randomized controlled trials are published, the medical community is, in a sense, operating within a crucible of crisis having to navigate therapeutic policy with little certainty. This principle holds true for thromboprophylaxis in patients with COVID-19 despite the numerous advancements in this field over the past decade.

A review of societal guidance shows there is universal agreement with regards to supporting standard doses of pharmacological prophylaxis in acutely ill patients either 
TABLE 2 Padua Risk Assessment Model for Medical Patients

\begin{tabular}{|c|c|c|}
\hline Baseline Features & Padua Score & Descriptions \\
\hline Active cancer & 3 & $\begin{array}{l}\text { Patients with local or distant metastases and/or in whom chemotherapy or } \\
\text { radiotherapy had been performed in the previous } 6 \text { mo }\end{array}$ \\
\hline Previous venous thromboembolism & 3 & Excludes superficial vein thrombosis \\
\hline Reduced mobility & 3 & $\begin{array}{l}\text { Bed rest with bathroom privileges (either due to patient's limitations or on } \\
\text { physician's order) for at least } 3 \mathrm{~d}\end{array}$ \\
\hline Already known thrombophilic condition & 3 & $\begin{array}{l}\text { Carriage of defects of antithrombin, proteins C or S, factor V Leiden, G20210A } \\
\text { prothrombin mutation, antiphospholipid syndrome }\end{array}$ \\
\hline Recent ( $\leq 1 \mathrm{mo}$ ) trauma and/or surgery & 2 & \\
\hline Aged $\geq 70 y$ & 1 & \\
\hline Heart and/or respiratory failure & 1 & \\
\hline $\begin{array}{l}\text { Acute myocardial infarction or acute } \\
\text { ischemic stroke }\end{array}$ & 1 & \\
\hline $\begin{array}{l}\text { Acute infection and/or rheumatological } \\
\text { disorder }\end{array}$ & 1 & \\
\hline Body mass index $\geq 30$ & 1 & \\
\hline Ongoing hormonal treatment & 1 & \\
\hline
\end{tabular}

when universally applied or guided by a RAM as well as the use of universal thromboprophylaxis in critically ill patients. All societies discourage the use of antiplatelet therapy for arterial thrombosis prevention and advocate for mechanical compression in patients with contraindications to pharmacologic anticoagulation. Beyond this, divergence between guidance statements begins to appear. For example, societies do not currently agree on the role and approach for extended pharmacologic prophylaxis postdischarge. The differences between societal guidance speaks to the degree of uncertainty among leading experts, which is considered to be the logical outworking of the current level of evidence. Regardless, these guidance documents should be considered the best resource currently available.

The medical community is fortunate to have robust societies that have published guidance on thromboprophylaxis in patients with COVID-19. The novelty of COVID-19 precludes these societal guidance publications from being based on high-quality evidence, but at the very least, they provide insight into how leading experts in the field of thrombosis and hemostasis are currently navigating the therapeutic landscape.

While this paper provides a summary of the current guidance, evidence is evolving at an unprecedented pace. Facilities and anticoagulation leads should be actively and frequently evaluating literature and guidance to ensure their practices and policies remain current.

\section{Acknowledgments}

This material is the result of work supported with resources and the use of facilities at the VA Tennessee Valley Healthcare System in Nashville/Murfreesboro.

\section{Author disclosures}

The authors report no actual or potential conflicts of interest with regard to this article.

\section{Disclaimer}

The opinions expressed herein are those of the authors and do not necessarily reflect those of Federal Practitioner, Frontline Medical Communications Inc., the US Government, or any of its agencies. This article may discuss unlabeled or investigational use of certain drugs. Please review the complete prescribing information for specific drugs or drug combinations-including indications, contraindications, warnings, and adverse effects-before administering pharmacologic therapy to patients.

\section{References}

1. National Institutes of Health. Coronavirus disease 2019 (COVID-19) treatment guidelines. https://www covid19treatmentguidelines.nih.gov/whats-new/. Updated October 9, 2020. Accessed October 15, 2020.

2. Bikdeli B, Madhavan MV, Jimenez D, et al. COVID19 and thrombotic or thromboembolic disease: 
TABLE 3 Caprini Risk Assessment Model for Most Surgery Patients 8 ,a

\begin{tabular}{|c|c|c|c|}
\hline 1 Point & 2 Points & 3 Points & 5 Points \\
\hline Aged $41-60$ y & Aged $61-74$ y & Aged $\geq 75 y$ & Stroke $(<1 \mathrm{mo})$ \\
\hline Minor surgery planned & Arthroscopic surgery & History of VTE & Elective arthroplasty \\
\hline Body mass index $>25$ & Major open surgery (> $45 \mathrm{~min}$ ) & Family history of VTE & Hip, pelvis, or leg fracture \\
\hline Swollen legs (current) & Laparoscopic surgery (> $45 \mathrm{~min})$ & $\begin{array}{l}\text { Factor V Leiden } \\
\text { prothrombin } 20210 \mathrm{~A}\end{array}$ & Acute spinal cord injury $(<1 \mathrm{mo})$ \\
\hline Varicose veins & Malignancy (present or previous) & Lupus anticoagulant & \\
\hline Sepsis $(<1 \mathrm{mo})$ & Confined to bed (> $72 \mathrm{~h})$ & Anticardiolipin antibodies & \\
\hline $\begin{array}{l}\text { Serious lung disease including } \\
\text { pneumonia }(<1 \mathrm{mo})\end{array}$ & Immobilizing plaster cast & Elevated serum homocysteine & \\
\hline Abnormal pulmonary function (COPD) & \multirow[t]{6}{*}{ Central venous access/ PICC line } & $\begin{array}{l}\text { Heparin-induced } \\
\text { thrombocytopenia }\end{array}$ & \\
\hline Acute myocardial infarction & & \multirow{5}{*}{$\begin{array}{l}\text { Other congenital or acquired } \\
\text { thrombophilia }\end{array}$} & \\
\hline Congestive heart failure $(<1 \mathrm{mo})$ & & & \\
\hline Medical patient currently at bed rest & & & \\
\hline History of inflammatory bowel disease & & & \\
\hline History of prior major surgery $(<1 \mathrm{mo})$ & & & \\
\hline
\end{tabular}

For women:

Pregnancy or postpartum

History of unexplained or recurrent

spontaneous abortion

Oral contraceptives or hormone replacement

Abbreviations: COPD, chronic obstructive pulmonary disease; PICC, peripherally inserted central catheter; VTE, venous thromboembolism.

alnstructions: Use pharmacologic thromboprophylaxis if score $>3$.

implications for prevention, antithrombotic therapy, and follow-up: JACC state-of-the-art review. J Am Coll Cardiol. 2020;75(23):2950-2973. doi:10.1016/j.jacc.2020.04.031

3. Barnes GD, Burnett A, Allen A, et al. Thromboembolism and anticoagulant therapy during the COVID-19 pandemic: interim clinical guidance from the anticoagulation forum. J Thromb Thrombolysis. 2020;50(1):72-81. doi:10.1007/s11239-020-02138-z

4. Spyropoulos AC, Levy JH, Ageno W, et al. Scientific and Standardization Committee communication: Clinical guidance on the diagnosis, prevention, and treatment of venous thromboembolism in hospitalized patients with COVID-19. J Thromb Haemost. 2020;18(8):1859-1865. doi:10.1111/jth.14929

5. Moores LK, Tritschler T, Brosnahan S, et al. Prevention, Diagnosis, and Treatment of VTE in Patients With Coronavirus Disease 2019: CHEST Guideline and Expert Panel Report. Chest. 2020;158(3):1143-1163. doi:10.1016/j.chest.2020.05.559

6. Al-Samkari H, Karp Leaf RS, Dzik WH, et al. COVID-19 and coagulation: bleeding and thrombotic manifestations of SARS-CoV-2 infection. Blood. 2020;136(4):489-500. doi:10.1182/blood.2020006520.

7. van Dam LF, Kroft LJM, van der Wal LI, et al. Clinical and computed tomography characteristics of COVID-19 associated acute pulmonary embolism: a different phenotype of thrombotic disease?. Thromb Res. 2020;193:86-89. doi:10.1016/j.thromres.2020.06.010

8. Kahn SR, Lim W, Dunn AS, et al. Prevention of VTE in nonsurgical patients: Antithrombotic Therapy and Prevention of Thrombosis, 9th ed: American College of Chest Physicians Evidence-Based Clinical Practice Guidelines. Chest. 2012;141(suppl 2):e195S-e226S. doi:10.1378/chest.11-2296

9. Gould MK, Garcia DA, Wren SM, et al. Prevention of VTE in nonorthopedic surgical patients: Antithrombotic Therapy and Prevention of Thrombosis, 9th ed: American College of Chest Physicians Evidence-Based Clinical Practice Guidelines [published correction appears in Chest. 2012 May;141(5):1369]. Chest. 2012;141(suppl 2):e227S-e277S. doi:10.1378/chest.11-2297

10. ACOG Practice Bulletin No. 196 Summary: thromboembolism in pregnancy. Obstet Gynecol. 2018;132(1):243-248. doi:10.1097/AOG.0000000000002707

11. Royal College of Obstetricians and Gynaecologists. Reducing the risk of venous thromboembolism during pregnancy and the puerperium. Green-top Guideline. No. 37a. https://www.rcog.org.uk/globalassets/documents /guidelines/gtg-37a.pdf. Published April 2015. Accessed October 15, 2020

12. Nadkarni GN, Lala A, Bagiella E, et al. Anticoagulation, mortality, bleeding and pathology among patients hospitalized with COVID-19: a single health system study [published online ahead of print, 2020 Aug 24]. J Am Coll Cardiol. 2020;76(16):1815-1826. doi:10.1016/j.jacc.2020.08.041

13. US Department of Veterans Affairs. Department of Veterans Affairs COVID-19 national summary. https://www.ac cesstocare.va.gov/Healthcare/COVID19NationalSummary. Updated November 1, 2020. Accessed November 1, 2020.

14. George B, Gonzales S, Patel K, Petit S, Franck AJ, Bovio Franck J. Impact of a clinical decision-support tool on venous thromboembolism prophylaxis in acutely ill medical patients. J Pharm Technol. 2020;36(4):141-147. doi:10.1177/8755122520930288 